\title{
Innovation in the Undergraduate Microelectronics Programmes at the University of Southampton
}

\author{
Robert G. Maunder - Director of Programmes \\ Department of Electronics and Computer Science, University of Southampton, Hampshire, SO17 1BJ, UK \\ Email: rm@ecs.soton.ac.uk
}

\begin{abstract}
This paper offers a programme-level discussion of the innovations that underpin the undergraduate microelectronics and related programmes in the department of Electronics and Computer Science (ECS) at the University of Southampton (UoS). These innovations include novel courses, laboratories and design projects, international education at The UoS Malaysia Campus (USMC), as well as the use of multimedia. Following this, the enhancement of the student experience and collaboration with industry is discussed.
\end{abstract}

\section{INTRODUCTION}

This paper offers a programme-level discussion of the innovations that underpin the undergraduate microelectronics and related programmes in the department of Electronics and Computer Science (ECS) at the University of Southampton (UoS). A key philosophy in the design of these programmes is striking an appropriate balance between theory and practice. In this way, we aim to develop our undergraduates into engineers having the knowledge and understanding required to design systems, as well as the practical skills and experience required to implement them. This not only enhances the employability of our graduates, but provides exciting and engaging programmes that develops our students' passion for microelectronics. This paper is organised as follows. The structures of these programmes are described in Section II. Their innovative features are discussed in Section III, including novel courses, laboratories and design projects, international education, as well as the use of multimedia. Then, the enhancement of the student experience is discussed in Section IV, while Section V discusses collaboration with industry in these programmes. Finally, conclusions and recommendations are offered in Section VI.

\section{Programme Structures}

In ECS, we offer four sets of undergraduate programmes that are related to microelectronics, namely Electronic Engineering (EL), Electrical \& Electronic Engineering (EEE), Electrical Engineering (EE) and Electromechanical Engineering (EM), as shown in Figure 1. The EL programmes have a particular focus on microelectronics and are marketed as covering small devices that use electricity to convey information. By contrast, the EE and EM programmes focus on big systems, that use electricity to convey power and to control machines, respectively. However, the EE and EM programmes also include extensive coverage of microelectronics, since

978-1-4673-8584-8/16/\$31.00 (C2016 IEEE

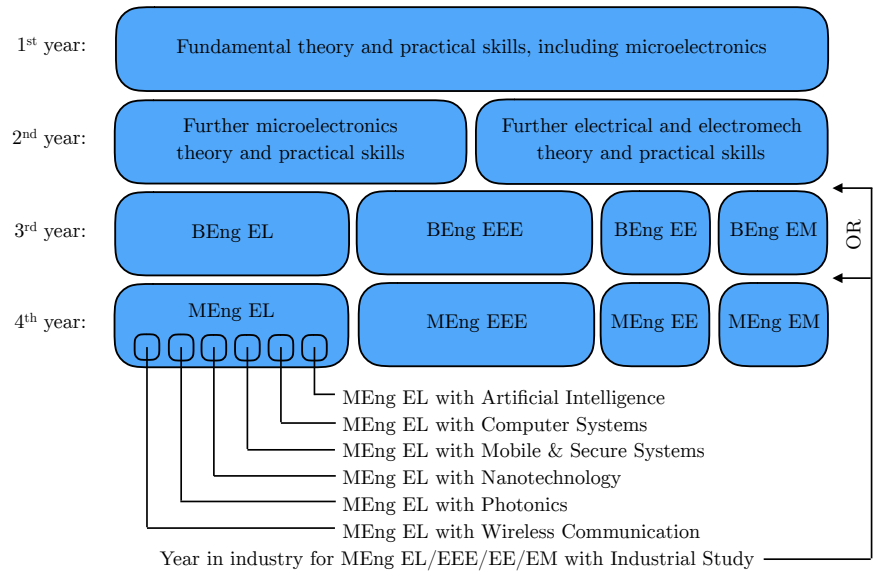

Fig. 1. Structure of the Electronic Engineering (EL), Electrical \& Electronic Engineering (EEE), Electrical Engineering (EE) and Electromechanical Engineering (EM) programmes at ECS.

these are vital components of electrical and electromechanical systems. Finally, the EEE programmes over-arch the EL, EE and EM programmes, offering the greatest flexibility for the students to tailor their undergraduate degrees to their own particular interests and career aspirations.

Within each set of programmes, we offer Bachelor of Engineering (BEng), Master of Engineering (MEng) and MEng with Industrial Studies (IS) variants, which have durations of three, four and five years, respectively. As shown in Figure 1, the first year is (mostly) common between all EL, EEE, EE and EM programmes, allowing students to transfer between these programmes during their first year, provided that they have met certain academic requirements. The second year of these programmes is common between the BEng, MEng and MEng with IS variants of these programmes, allowing transfer between variants having different durations during the first two years. However, the second year differs between the EL, EEE, EE and EM programmes, as they diverge from each other towards the different focuses described above. The first and second years of these programmes each comprise eight modules, which are (mostly) compulsory. This ensures that all students obtain a strong foundation within the first two years, enabling us to maximise the degree of flexibility that we can offer to students in their final years. More specifically, third year students select five modules from a portfolio of over 60 modules, which include some broadening options 
offered from across UoS. This portfolio also includes some modules that are positioned at the interface between microelectronics and computer science, which is a key benefit of offering microelectronics programmes in the same department as computer science programmes. In addition to these five modules, each third year student is paired with an academic supervisor according to mutual interests, in order to complete an individual project, which is typically research-based, as will be exemplified in Section III. Likewise, fourth year MEng students select five modules from a different portfolio of over 50 modules, which are also offered to postgraduate Master of Science (MSc) students in ECS and in the Optoelectronics Research Centre (ORC). Additionally, each fourth year MEng student is grouped with three or four other students and with an academic supervisor according to mutual interests. These groups of students complete a Group Design Project (GDP), which is typically industry-based, as detailed in Section V. Furthermore, we offer several MEng EL programme variants, each of which has a different particular specialisation, namely Artificial Intelligence (AI), Computer Systems (CS), Mobile \& Secure Systems (MSS), Nanotechnology, Photonics or Wireless Communication (WC), as shown in Figure 1. By selecting third and fourth year modules from particular groups, these students benefit from having these specialisations recognised in their degree title, enhancing their employability within the corresponding specialisation. In particular, the AI, CS and MSS specialisations are facilitated by the scope of ECS, which encompasses microelectronics and computer science, as described above. Finally, MEng with IS students spend a year in industry, either between their second and third years of study, or between their third and fourth years of study, as shown in Figure 1 and as will be discussed in Section V.

\section{InNOVATIVE PROGRAMME DESIGN}

This section discusses innovative programme design in the microelectronics programmes at ECS. Section III-A discusses novel modules, laboratories and design projects. Section III-B describes ECS's international education offering in Malaysia. Finally, the use of multimedia in the above-mentioned programmes is discussed in Section III-C.

\section{A. Novel modules, laboratories and design projects}

As described in Section I, a key philosophy in the design of the microelectronics programmes at ECS is striking an appropriate balance between theory and practice. This philosophy is particularly apparent during the students' first two years of study, in which (nearly) all modules have large parts of their assessment derived from multiple types of learning activity, including laboratory sessions, coursework and examinations. In the third and fourth years of study, the students have the freedom to select modules according to their own particular interests and career aspirations, as described in Section II. Furthermore, depending on whether these aspirations are more research or industry focused, the third and fourth years give the opportunity to tailor the balance between theory and practice, as well as between different types of learning activities. More specifically, some modules are purely assessed by examination, while others are assessed using only laboratory sessions or coursework, with other modules occupying various points in the spectrum between these extremes. The following subsections discuss the various mechanisms through which the microelectronics and related programmes at ECS apply the theory developed in lectures into practice.

1) Laboratory programme: During the first and second years of study, (nearly) all of the modules include several practical laboratory sessions, which complement the theory developed during the corresponding lectures. However, the organisation and running of these laboratory sessions is centralised under the umbrella of a laboratory programme. In addition to these technical laboratory sessions, the laboratory programme also contains several 'skills' laboratory sessions and briefings. These cover topics such as logbook keeping, laboratory equipment, experimental design, circuit simulation, Printed Circuit Board (PCB) layout, circuit construction, fault finding, experimental measurement, statistics and uncertainty, professional practice and ethics, health and safety, project management, technical writing, academic integrity, presentation and entrepreneurship. In addition to developing important skills for the undergraduates, these activities address many of the requirements of UK Standard for Professional Engineering Competence (UK-SPEC) and Institution of Engineering and Technology (IET) accreditation. There are several advantages to centralising all technical and skills laboratory sessions under the umbrella of a laboratory programme. In particular, this enables the efficient timetabling of the laboratory space, as well as ensuring consistent marking schemes, Quality Assurance (QA) processes and student expectations. All laboratory notes are presented in a common format and are accompanied by supervisor notes, which ensure consistent supervision practices by the team of postgraduate and academic demonstrators.

2) Design exercises: At UoS, each 12-week semester is followed by two exam weeks. However, the students sit only a single exam during the exam weeks that follow the first semester of the first year. This frees up the rest of the time for design exercises, which bring together the theory and practice that has been developed during the modules and the laboratories that the students have completed so far. More specifically, the design exercises bridge the ELEC1200 Electronic Circuits, ELEC1201 Programming and ELEC1202 Digital Systems \& Microprocessors modules, emphasising that their topics are not independent. The D1 design exercise tasks the students with designing and building a boost converter power supply circuit, which is controlled by an AVR microprocessor having a serial communication link with an application running on a PC. Meanwhile, the D2 design exercise tasks the students with programming a Complex Programmable Logic Device (CPLD) to behave as a simple microprocessor, which they must program to perform simple encryption and decryption operations. These design exercises make use of the Micro Arcana AVR and CPLD development boards, which are introduced during laboratory sessions earlier in the semester. As shown in Figure 2, these development boards have been designed 


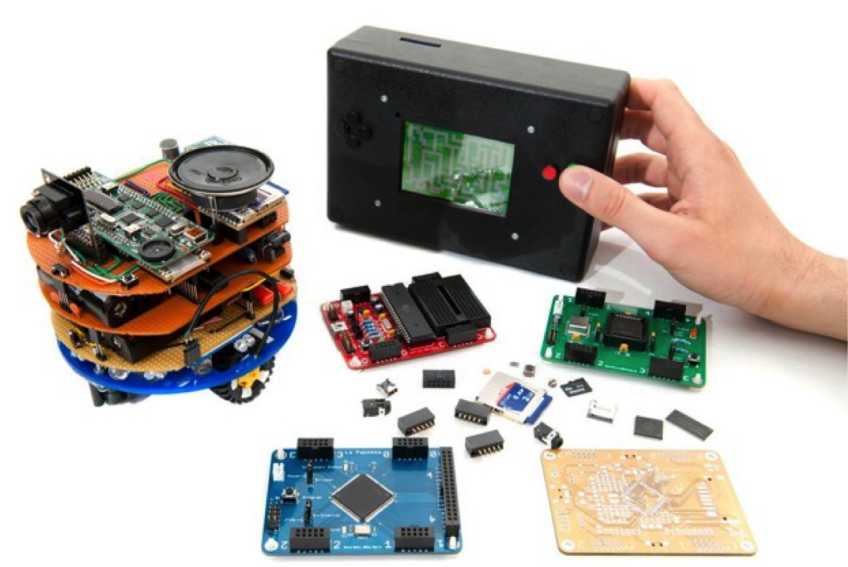

Fig. 2. Example D4 projects and the Micro Arcana development boards for AVR microprocessor (red), CPLD (green), FPGA (blue) and ARM microprocessor (yellow).

at ECS to have common programming and Input/Output (I/O) interfaces, giving the students a platform for rapid prototyping. The students build these development boards themselves and can keep them for use in their own hobby projects. To complement these development boards, the students are also provided with tool kits, as well as software and hardware that allows their PCs to be used as mixed signal oscilloscopes. In this way, we encourage the students to view microelectronics as not only a means to fulfil their career aspirations, but also as an interesting hobby in which they can develop a passion, that they can direct back into their studies.

In their second year of study, the students take a module which is dedicated to design exercises relevant to their degree programme, namely ELEC2205 EL Design, ELEC2209 EE/EM Design or ELEC2217 EEE Design. In the D1 design exercise, the EL and EEE students are tasked with programming a CPLD to behave as an unsigned binary sequential multiplier, building on the first-year D2 design exercise. In the second-year D2 design exercise, the EL and EEE students design, synthesise, simulate and layout an Integrated Circuit (IC), which can perform various independent arithmetic and logical operations, as was detailed in [1]. More specifically, the students undertake this work in groups of six students, where the layouts produced by each group are combined onto different partitions of a single IC design, as shown in Figure 3. An instance of this IC is fabricated and packaged for each group, allowing them to validate their design and compare their measurements with their simulations. A key aim of this design exercise is for the students to gain skills and experience in systematic design techniques, which minimise the risk of design errors. In order to support this, the students can submit their designs to online automated test harnesses, which provide test reports that can be used to identify and remove design errors. Owing to this approach, most teams produce designs in which most arithmetic and logical operations work correctly. Note that an 'all or nothing' outcome is avoided by tasking the students with implementing several different arithmetic

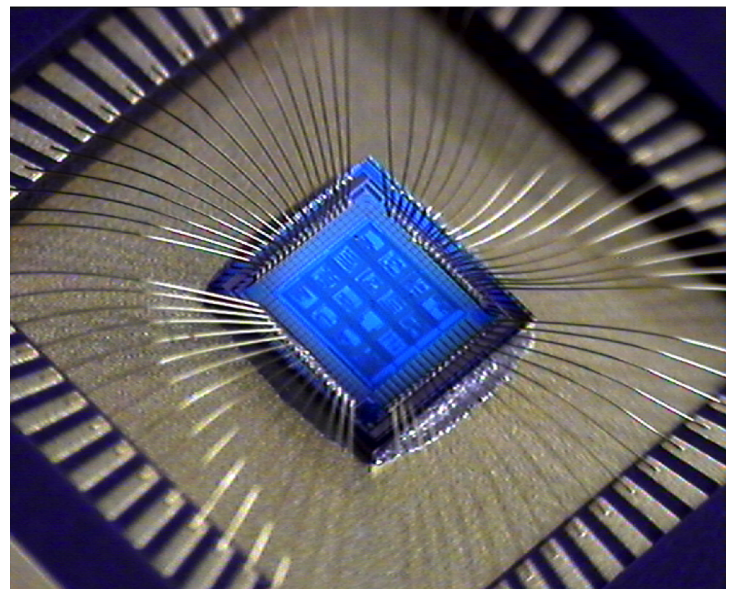

Fig. 3. Combination of the layouts produced by 16 second-year D2 design exercise groups into a single IC and its packaging.

and logical operations, rather than giving them a single more sophisticated task. The D3 design exercise requires the EL students to use simulation tools to design and build a multistage transistor amplifier circuit.

However, the second-year design exercises having the greatest contributions to the above mentioned modules are the system design exercises. The EL students complete the D4 system design exercise, which tasks the students with a different set of design requirements each year. In recent years, these requirements have considered an oscilloscope, a handheld video game system (as exemplified in Figure 2), a football playing robot (as exemplified in Figure 2), a home automation system, a one-man band audio synthesiser, a wireless communication system and a spherical remote-controlled vehicle. The D4 system design exercise is completed intensively over three weeks, during which the students have exclusive use of the EL laboratory area in between their lectures. The students work in groups of six, although the assessment is mainly weighted towards their individual contributions, rather than to the overall group achievement. This reduces the pressure that the students impose on each other, allowing them to develop their team-working maturity at their own pace. A key aim of the D4 system design exercise is to give the students the opportunity to set their own targets and to give them an experience that will help them to set realistic expectations for future group projects. In particular, we find that many groups are initially over-ambitious and underestimate the challenges associated with team working and system integration. In order to address this, the students' first task is to develop project proposals, which define the specification that they will target during the design and construction stages. We then run design clinics to give the students feedback on their proposals. By contrast, the EEE students complete the D5 system design exercise, which tasks the students with designing and building a microprocessor-controlled smart electricity meter system. Meanwhile, the EE and EM students complete the Rover system design exercise, which tasks the students with designing 
and building a microprocessor-controlled autonomous robot, which can navigate along a prescribed track. These design exercises have similar aims to D4, but are run over the course of the semester, rather than intensively.

3) Projects: As described in Section II, each ECS student completes an individual project during their third year of study, which is typically research-based. More specifically, these projects are typically informed by and contribute to the research of the supervisor's research group, sometimes resulting in the publication of the students' work. In turn, this research often informs our teaching. For example, [2] details a third-year individual project that investigated the practical challenges of wireless communication using Software-Defined Radio (SDR) equipment. It is difficult for students to gain skills and experience in overcoming these practical challenges using only simulation, which is the main approach used in wireless communication education around the world. Motivated by the findings of this third-year individual project, we have introduced the use of SDR equipment into the abovelisted undergraduate programmes.

By contrast, the fourth year GDP is typically industry-based, as will be detailed in Section V. However, some GDPs contribute to on-going multi-disciplinary student projects, which span multiple departments and years. For example, the UoS Small Satellite (UoS3) project is developing a cube satellite [3], which will be launched from the International Space Station and used to provide ground-truth measurements to aid research on predicting re-entry paths for satellites in decaying orbits. To date, the UoS3 project has included three ECS GDPs, which have developed the controller, communications and power supply modules. In addition to this, the UoS3 project has included student projects from the departments of Mechanical Engineering, Physics \& Astronomy and the Winchester School of Art, where the latter has produced materials for public engagement.

\section{B. International education at USMC}

The UoS Malaysia Campus (USMC) is a branch campus of UoS, located in the EduCity development in Iskandar, Malaysia. EduCity brings together branch campuses from several different universities around the world, each of which offers different degree programmes. USMC offers an Engineering foundation year programme, as well as the abovementioned MEng EEE programme and an MEng Mechanical Engineering programme. The students of these MEng programmes complete their first and second years of study at USMC, before transferring to Southampton to complete their third and fourth years. In this way, the students benefit from an international education, having smaller class sizes during the first and second years when the modules are all compulsory, but without missing out on the wide range of optional modules available at Southampton in the third and fourth years. During their time at USMC, the students complete the same modules as the students in Southampton, using the same lecture materials, courseworks, laboratory sessions and examinations. The modules are delivered by a combination of locally-employed academics and 'flying-faculty', who are academics from Southampton that visit USMC for two weeks at a time, to deliver a part of a module intensively. In this way, the academics and students at USMC benefit from regular contact with academics from Southampton. This contact is further enhanced during the summer, when academics from USMC have the opportunity to visit Southampton to complete the Postgraduate Certificate of Academic Practice (PCAP) and gain fellowship of the Higher Education Academy (HEA), as well as to supervise MSc projects.

\section{Multimedia}

ECS has a proven track record in technology enhanced learning [4], having pioneered online systems for the electronic submission of coursework and automated test harnesses that give students instant feedback on their submissions, as described in Section III-A. Furthermore, software and equipment for recording lectures is provided in all lecture theatres at UoS, as well as in the ECS laboratories. This year, UoS will be rolling out the Synote software [5], which has been developed in ECS to automatically generate searchable subtitles for recorded lectures and enable the crowd-sourced correction of any errors that result from this process. Furthermore, the ECS website and internet are powered by linked data, which ensures that all module web pages are automatically updated whenever their syllabuses are updated [6]. Linked data also powers the project allocation system, which matches students with supervisors according to mutual interests expressed on their profile web pages. Finally, UoS has an online repository named EdShare [7], which allows ECS academics to share their teaching materials with other academics around the world.

\section{EnHANCING THE Student ExPERIEnCE}

All ECS students take part in the Jump Start programme [8], at the start of the first year of study in Southampton or when transferring from USMC to Southampton at the start of the their third year of study. This programme is intended to help students transition from a typically smaller-scale education provision at A Level or at USMC, to the large-scale education provision of ECS in Southampton, where the microelectronics and related programmes constitute over 50 academics, over 100 modules and over 500 students, spread over the four years shown in Figure 1. This enriches the student experience by ensuring that all students know how to engage with ECS systems and processes, as well as how to get help. Jump Start also includes social events, which provide opportunities for students to make friends and to build support networks.

This year, the student experience has also been enhanced by a $£ 4 \mathrm{~m}$ investment, which has converted the previously-separate EL, EEE, EE and EM teaching laboratories into a single open-plan space, which can be utilised much more efficiently and flexibly. This investment has also created a new projects laboratory, which provides a consistent space where third-year individual project students and fourth-year GDP students can work in between their lectures. Finally, the investment has also refurbished the ECS computer laboratory, which is open 
from early in the morning to late in the evening, allowing students to complete their coursework in a social environment. The investment has also funded new equipment, which includes high performance computers throughout the abovementioned laboratories, as well as specially-designed work benches for the project and teaching laboratories. Each work bench has two computer monitors, keyboards, mice and chairs, allowing two students to work independently. Alternatively, the monitors can be moved together to allow the students to work in pairs. Each work bench also includes three power supplies, a signal generator, a digital multimeter and a highperformance digital/analogue/RF oscilloscope. Furthermore, some work benches include specialist EE and EM equipment, such as three-phase power supplies, motors and generators.

\section{COllaboration With Industry}

As described in Section II, the fourth-year GDP is typically industry-based. More specifically, in addition to having an academic supervisor, each group of students has an industrial customer. While the academic supervisor monitors the students' progress and advises them on the assessment of the GDP, it is the industrial customer that specifies its topic and requirements. These are typically informed by and contributes to the activities of the industrial customer, which range from spin-outs of ECS [9], to multi-national corporations. This year, the industrial customers include Head Communications, ARM, KBR, City Farm Systems, SPI Lasers, Interdigital Technology and Synote. A key part of the assessment of the GDP is the degree to which it provides value to this customer. In this way, the GDP is intended to model an industrial team project. In particular, the students are required to take on several project management roles, including technical specification, customer point of contact, requisitions, producing agendas and minutes for meetings, as well as documentation management. In contrast to the second-year group design exercises, the assessment of the GDP is weighted towards the group achievement, rather than the individual contributions. In this way, the students are motivated to apply the team-working maturity that they have developed throughout their degrees, as described in Section III.

In addition to the GDP, students of the five-year MEng with IS programmes gain industrial experience during their year in industry, as described in Section II. Throughout this year, the students take a paid placement at a company, where they complete industrial projects under the supervision of an industrial supervisor. They also have an academic supervisor, who visits the student and the industrial supervisor on a regular basis, in order to complete QA processes and to assess the student's progress reports. In this way, the students gain academic credit and graduate with an enhanced MEng degree. These programmes are particularly valuable to overseas students, who typically have visa conditions that prevent them from taking industrial placements that do not earn academic credit.

There are a number of other mechanisms through which the microelectronics and related programmes benefit from collaborations with industry, including careers fairs, donation of laboratory equipment and sponsorship of prizes.

\section{CONCLUSION AND RECOMMENDATIONS}

This paper has provided a programme-level discussion of the innovations that underpin the undergraduate microelectronics and related programmes in ECS at UoS. These innovations may be summarised by the following set of recommendations, which which other institutions may wish to consider for their undergraduate microelectronics programmes.

- Microelectronics programmes may be flexibly structured to give students the choice of specialising in particular areas with enhanced depth, or of maintaining a broader coverage with enhance breadth.

- Programme variants having specialised degree titles may be offered in order to enhance graduate employability within these areas of specialisation.

- A (mostly) common and compulsory first year between programmes grants students the ability to defer the decision of whether and how to specialise until after they have had a flavour of all subject areas.

- Having (mostly) compulsory modules in the second year as well allows all foundation subject areas to be covered in a time-efficient manner, allowing a maximal degree of flexibility to be offered in the final years.

- Offering the first and second years at international branch campuses allows students from these regions to benefit from reduced costs and smaller class sizes, before transferring to the parent university campus in the final years to benefit from a wide variety of optional modules.

- The number of optional modules that can be sustainably offered in the final years of undergraduate programmes can be greatly enhanced by offering well-aligned MSc programmes in the same department.

- Teaching microelectronics in the same department as computer science enhances the integration of modules that are positioned at the interface of these subjects.

- An appropriate balance between theory and practice may be struck by adopting a variety of assessments throughout the programme, including examinations, courseworks, laboratory sessions, design exercises and projects.

- By delivering the laboratory sessions of all modules under the same umbrella, their organisation and running can be harmonised, offering benefits in timetabling, QA and student experience.

- Many of the UK-SPEC and IET accreditation requirements can be met by including 'skills' laboratory sessions and briefings in the laboratory programme.

- Development boards and tools can be provided to students, so that they can complete microelectronics hobby projects at home and develop a passion that can be directed back into their studies.

- Spare time during exam weeks can be used for design exercises, which bring together the material covered in the modules of the previous semester.

- Entire modules may be devoted to design exercises, enabling team projects that develop not only students' technical skills, but also their team-, time- and project- 
management skills.

- Automated test harnesses may be used to give students instant feedback on their designs, enhancing their learning and student experience.

- By changing the specification of design exercises each year, they can be kept fresh and innovative, enhancing the student experience.

- In earlier years, the assessment of team exercises may be weighted towards the students' individual efforts in order to reduce the pressure that they impose on each other, allowing them to develop their team-working maturity at their own pace.

- Individual projects that comprise a high number of credits offer an opportunity in later years to link the institution's research into the teaching, benefiting both activities.

- Similarly, group projects that comprise a high number of credits offer an opportunity in later years to give students the experience of having an industrial customer, enhancing their professionalism and management skills.

- By linking student projects over different departments and years, students can be given the experience of contributing to ambitious large-scale on-going projects, exposing them to challenges associated with scale and external interfacing.

- Multimedia tools for lecture recording and captioning, linked data intranet generation, automated project allocation and the sharing of teaching materials can enhance the student experience and efficiency of the department.

- An induction programme may be offered to help students transition from the smaller-scale education provision at $\mathrm{A}$ Level or at international branch campuses, enriching the student experience.

- Credit-bearing industrial placements offer an opportunity for international students to gain valuable work experience within the constraints of their visa conditions, enhancing graduate employability and the student experience.

These innovations have contributed to the strong league table positions of the undergraduate microelectronics and related programmes in ECS at UoS. More specifically, these programmes have been ranked first in the Guardian league table in 2011-14 and 2016, top three in the Complete University Guide in 2010-16, as well as top three in the Sunday Times league table in 2012-13 and 2015-16. In the 2015 National Student Survey (NSS), these programmes achieved strong student satisfaction scores, with MEng EE achieving a score of $100 \%$. In the 2015 Destination of Higher Education Leavers (DHEL) survey, the graduates of these programmes enjoyed strong career prospects, with MEng EL students achieving an average salary of $£ 29 \mathrm{k}$, which is significantly higher than the $£ 25 \mathrm{k}$ sector average. Furthermore, $90 \%$ of the BEng and MEng EE students were employed or completing further study within six months of graduating.

\section{ACKNOWLEDGEMENT}

The author wishes to thank his colleagues who have developed the programmes and innovations described in this paper. Of particular mention are M. C. French, S. R. Gunn, C. J. Gutteridge, N. R. Harris, T. J. Kasmierski, P. L. Lewin, J. K. Lewis, S. Mahmoodi, G. V. Merrett, D. Oakley, M. Rotaru, K.-P. Zauner, M. Zwolinski and all those listed below.

\section{REFERENCES}

[1] P. Wilson, I. McNally, M. Swabey, and B. M. Al-Hashimi, "IC design and manufacture for undergraduates: Theory, design and practice," in Proc. Euro. Workshop Microelectronics Education, Budapest, Hungary, May 2008, pp. 22-23. [Online]. Available: http://eprints.soton.ac.uk/265839/

[2] M. El-Hajjar, Q. Nguyen, R. G. Maunder, and S. X. Ng, "Demonstrating the practical challenges of wireless communications using USRP," IEEE Commun. Mag., vol. 52, no. 5, pp. 194-201, May 2014. [Online]. Available: http://eprints.soton.ac.uk/364267/

[3] A. A. Lidtke, C. Rumpf, A. Tatnall, H. G. Lewis, S. J. Walker, M. Taylor, R. C. Fear, A. S. Weddell, R. G. Maunder, and J. R. Bantock, "Enhancing spaceflight safety with UOS3 cubesat," in Proc. ESA Symp. Space Educational Activities, Padova, Italy, Dec. 2015. [Online]. Available: http://eprints.soton.ac.uk/384750/

[4] S. A. White and M. McPherson, "Consolidating understanding: How to transform higher education through technology enhanced learning," in Proc. Euro. Conf. Technology Enhanced Learning, Maastricht, The Netherlands, Apr. 2008. [Online]. Available: http://eprints.soton.ac.uk/265384/

[5] M. Wald and Y. Li, "Synote: Important enhancements to learning with recorded lectures," in Proc. IEEE Int. Conf. Advanced Learning Technologies, Rome, Italy, Jul. 2012, pp. 521-525. [Online]. Available: http://eprints.soton.ac.uk/340722/

[6] S. A. White, H. C. Davis, K. Dickens, and S. Fielding, "Crafting a rich and personal blending learning environment: An institutional case study from a STEM perspective," in Proc. Int. Conf. Computer Supported Education, Aachen, Germany, May 2013. [Online]. Available: http://eprints.soton.ac.uk/346929/

[7] D. Morris, J. Hey, H. C. Davis, S. A. White, L. A. Carr, T. Miles-Board, and S. Francois, "EdShare: Towards sharing resources for learning and teaching at the University of Southampton," in Proc. Int. Conf. on Open Repositories, Southampton, UK, Apr. 2008. [Online]. Available: http://eprints.soton.ac.uk/265381/

[8] S. A. White and L. A. Carr, "Brave new world: Can we engineer a better start for freshers?" in Proc. Frontiers Education Annual Conf., Oct. 2005. [Online]. Available: http://eprints.soton.ac.uk/261631/

[9] E. Walls, M. Santer, G. Wills, and J. Vass, "The Dreams Plan: A Blupoint strategy for e-education provision in South Africa," Electronic Journal Information Systems Developing Countries, vol. 70, no. 7, pp. 1-24, 2015. 